\title{
SOBRE O STATUS DE PPS EM ESTRUTURAS COM VERBOS DO TIPO IR E CHEGAR: COMPLEMENTO OU ADJUNTO?'
}

\author{
Jair Gomes de Farias ${ }^{2}$ \\ Universidade Federal de Alagoas
}

Resumo: Neste artigo, eu convoco a discussão nada pacífica sobre o estatuto de sintagmas preposicionais (PPs) encabeçados pelas preposições $a$, para e em em estruturas frásicas construídas com verbos do tipo ir e chegar na gramática do português. Baseado nos fundamentos da Teoria de Princípios e Parâmentros (CHOMSKY, 1986 e 1993), mais precisamente, na relação Léxico-Sintaxe, argumento, então, que, contrariamente ao que é comumente dado na literatura, os PPs nesses contextos não são adjuntos, mas sim complementos; não podem ser núcleo de uma small clause; não são opcionais na sintaxe.

Palavras-Chave: Preposição; adjunção vs. complementação; sintaxe.

\section{Introdução}

Tratar a questão da distinção entre complementos e adjuntos, quer seja em relação ao verbo, quer seja em relação ao nome, requer, antes de tudo, a explicitação de mecanismos estruturais que apontem para uma classificação consistente quanto ao comportamento sintático de complementos $v s$. adjuntos. Isso implica convocar uma questão nada estável ou pacífica nos estudos lingüísticos, desde os estudos iniciais da gramática tradicional até os estudos mais recentes no âmbito de uma teoria gramatical: A TRANSITIVIDADE.

Para fins do viés argumentativo deste trabalho, assumo que a transitividade verbal vai ser instanciada pelo princípio de predicação ${ }^{3}$,

1 Para uma discussão aprofundada das questões apresentadas neste artigo, ver minha tese de doutorado intitulada Aspectos da Sintaxe de Preposições no Português (2005).

2 Doutor em Lingüística pelo Programa de Pós-Graduação em Letras e Lingüística da UFAL e Professor Substituto de Linguística, lotado no Departamento de Letras Clássicas e Vernáculas (LCV). 
ou seja, a noção de subcategorização e posterior função sintática do sintagma, se complemento ou adjunto, está estritamente relacionada à satisfação de papéis semânticos requeridos pelo núcleo predicador, seja ele $\mathrm{A}, \mathrm{N}, \mathrm{V}$ ou $\mathrm{P}$.

Tomando como aporte as questões acima explicitadas e dando especial enfoque à observância do comportamento de PPs em contextos estruturais construídos com verbos do tipo ir e chegar, é pertinente destacar que por serem esses verbos classificados como inacusativos $^{4}$, na Teoria Gerativa, ou seja, aquele tipo de verbo que seleciona apenas um argumento, e este é interno, com função- $\theta$ Tema, o PP exibido por esse tipo de verbo é analisado, pelo menos, sob três diferentes enfoques: (1) como adjunto, por serem as preposições $a$, para e em que encabeçam seus complementos itens lexicais plenos, e, portanto, barreira à atribuição de papel- $\theta$ pelo núcleo predicador verbal (cf. OLIVEIRA, 2003); (2) como núcleo de uma small clause, o que se traduz numa tentativa de preservar a binaridade e a classificação desse tipo de verbo como inacusativo (cf. HOEKSTRA E MULDER, 1990; LEVIN E RAPAPPORT-HOVAV, 1995; DUARTE, 2003); (3) como sendo opcional na sintaxe, em que o PP nas frases com esse tipo de verbo sofre algum tipo de operação de saturação no léxico, a exemplo de verbos acusativos que têm seu complemento saturado e pode vir não realizado foneticamente: verbos do tipo comer (cf. XAVIER, 1989).

Neste artigo, a minha resposta é negativa às três possibilidades de classificaçâto quanto ao status do PP em frases com verbos do tipo ir e chegar como logo acima pontuadas. Adoto, então, com Farias

3 Assumo, com Viotti (1999, p.126), a designação de Predicação "como um correlato semântico de operações constitutivas da sintaxe, decorrente da aplicação do princípio de composicionalidade". Nesse sentido, como a Predicação é vista como a instanciação do princípio de composicionalidade, papéis temáticos devem ser flexíveis de maneira que possam refletir todas as interpretações permitidas pela aplicação de tal princípio entre os núcleos predicadores de um sintagma ou de uma frase.

4 Para uma discussão mais aprofundada quanto à checagem da inacusatividade com verbos do tipo ir e chegar e a verificação de como o PP co-especifica esse tipo de verbo, afetando sua valência, ver Farias (2005). 
(2005), que o PP é complemento legítimo desse tipo de verbo, e não adjunto; não pode ser tratado como núcleo de uma small clause; não é opcional na sintaxe.

A discussão e apresentação de evidências empíricas que norteiam minha argumentação estão assim compreendidas: na seção 2 , traço um panorama geral da situação e de problemas quanto ao status do PP em frases com verbos do tipo ir e chegar, seja na tradição gramatical, seja na Teoria Gerativa; na seção 3 e subseções, aponto as evidências que classificam o PP dessas construções como complemento e, na seção 4 , faço um arremate final, trazendo as questões centrais discutidas ao longo deste artigo.

\section{O Problema}

Como já foi apresentado na introdução deste trabalho, a classificação de sintagma como complemento ou adjunto do verbo está estritamente relacionada à satisfação de papéis semânticos requeridos pelo núcleo predicador verbal. A título de ilustração, observe os seguintes exemplos:

(1) O João construiu a casa.

(2) O João deu o livro a/pra Maria.

(3) O João trabalha em Maceió.

(4) O João foi a/para/em Lisboa.

(5) O João chegou a/em Maceió.

Observando os exemplos dados, pode-se verificar que em (1) o verbo construir apresenta em sua entrada lexical dois argumentos: um argumento interno, resultado do processo de construir (a casa) e um argumento externo (o João), agente e origem do evento de processo do verbo que, se forem alçados, terão, respectivamente a função sintática de sujeito e de objeto direto da frase. Em (2), o verbo dar, por ser um verbo de três lugares seleciona dois argumentos internos (o livro e a Maria), que satisfazem as funções semânticas de Tema e de Beneficiário, respectivamente, e o argumento externo (o João), agente do evento requerido pelo tipo do verbo. Neste caso, tem-se na sintaxe, um sujeito, um objeto direto e um objeto indireto, sendo este último, sintaticamente identificado por ser encabeçado pela preposição da 
qual recebe Caso inerente. No exemplo em (3), verifica-se que, por ser um verbo do tipo intransitivo/inergativo, apresenta em sua entrada lexical apenas um único argumento, e este é externo (o João). A presença de um PP no predicado não implica assumir que ele seja um complemento desse tipo de verbo, pois como mais adiante mostrarei, nesse caso específico, quando a estrutura é clivada, pode-se haver quebra de adjacência entre o verbo e seu complemento, ao passo que, com verbos do tipo ir e chegar, não. Pontua-se, daí, que o PP exibido no exemplo (3) é um adjunto, cuja preposição que o encabeça é ela sozinha responsável pela atribuição de papel- $\theta$ e de Caso. Já os exemplos dados em (4) e (5) apresentam um comportamento diferençado em relação aos demais. Uma das questões controversas é: qual a entrada lexical desse tipo de verbo, haja vista aceitarem construções inacusativas, nas quais o PP pode ou não vir foneticamente e a função semântica do "sujeito" vai ser sempre a de Tema, como mostram os exemplos em (6) e (7):

(6) A carta chegou

(7) A carta foi pra universidade

Como possível elicitação desse problema, assumo, com Farias (2004, 2005), que a Estrutura Argumental desses verbos é dada como se segue:

$$
\begin{aligned}
& \text { Ir } \theta_{1}, \theta_{2} \\
& \text { grelha }-\theta: \text { y (Tema/Agente), z (Lugar) } \\
& \text { subcategorização: +V, [- DP PP] } \\
& \text { Chegar } \theta_{1}, \theta_{2} \\
& \text { grelha - } \theta: \text { y (Tema/Agente), z (Lugar) } \\
& \text { subcategorização: +V, [- DP PP }]^{5}
\end{aligned}
$$

5 Mesmo apresentando uma entrada lexical comum, há evidências empíricas para se assumir que os verbos ir e chegar apresentam, em determinados contextos, um comportamento estrutural distinto na gramática do português, isso tem a ver com a seleção da preposição e do DP selecionado por P. Para melhores esclarecimentos, conferir Farias (2005). 
Ao tomar como base essa perspectiva de análise, assumo também que as construções inacusativas são derivadas dessa entrada lexical de base e têm a ver com propriedades predicativas advindas da estrutura lexical, instanciadas pelo princípio da co-composição (cf. PUSTEJOVSKY, 1998).

Bom, mas a questão central da minha discussão aqui neste artigo permanece em aberto: se o PP está foneticamente realizado nos dados em (4) e (5), é o suficiente para se assumir que esse PP é argumento interno de verbos do tipo ir e chegar? Pelo que já se verificou a partir da observação do dado em (3), é mesmo coerente assumir que não! Não é o simples fato de um sintagma vir foneticamente realizado que implica dizer que ele pode ser um complemento de um núcleo predicador, nesse caso, em especial de verbos do tipo ir e chegar.

Dessa observância, é pertinente pontuar que a questão da classificação quanto ao status do PP como complemento ou adjunto não configura um quadro estável dentro dos estudos lingüísticos, o que pode ser observado tanto no âmbito da tradição gramatical quanto no de uma teoria gramatical, e tem a ver com o traço categorial do verbo, o que supõe a problemática da transitividade verbal.

Numa perspectiva da tradição gramatical, Kury (1997), apresentando o veredicto de vários gramáticos, afirma que esses verbos exigem além de um argumento na posição de sujeito, um "complemento adverbial de lugar", e destaca:

Vários autores têm incluído esses verbos entre os transitivos: José Oiticica os denomina "verbos adverbiados"; Rocha Lima lhes chama "transitivos circunstancias"; Evanildo Bechara sugere o nome 'transitivos adverbiais', observando que, numa oração como "Irei à cidade", a cidade é complemento e não adjunto. Antenor Nascentes, embora os inclua entre os intransitivos, adverte: tratando-se de verbos intransitivos de movimento, o complemento de direção não pode ser considerado elemento meramente acessório (p. 33).

É interessante perceber, com o acima apresentado, que parece haver um indício de que o argumento preposicionado em sentenças 
construídas com esses tipos de verbo parece interferir na natureza sintático-semântica destes. Todavia a questão não está esclarecida!

No que diz respeito a estudos e análises desenvolvidos no âmbito da Teoria Gerativa, por serem esses verbos considerados inacusativos, o status do PP vai ser considerado, como já enunciado na introdução, ou como adjunto, ou como núcleo de uma small clause ou como opcional na sintaxe.

A idéia de se advogar que o PP de frases com verbos do tipo ir e chegar é um adjunto é devida à Oliveira (2003). Ela argumenta que, por serem as preposições $a$, para e em lexicalmente plenas nos contextos construídos com verbos de movimento, elas encabeçam adjuntos e não complementos, haja vista a conectividade casual e temática ser atribuída ao DP complemento subcategorizado por $\mathrm{P}$, unicamente por este núcleo predicador.

No que concerne à questão de o PP ser tratado ou nāo como núcleo de uma small clause remete à idéia inicial de Hoekstra e Mulder (1990), também adotada por Levin \& Rappaport-Hovav (1995), em que se considera que, por serem esses verbos inacusativos, selecionam não dois argumentos que satisfazem a função semântica do verbo, mas sim uma small clause com função- $\theta$ Tema, em que o DP pode ser movido para Spec, IP para checar EPP e Caso nominativo, este atribuído por cadeia. É pertinente também esclarecer que essa mesma idéia é adotada, para os dados do PE, por Duarte (2003, p.548) ao assumir que "esta subclasse de verbos determina estruturas idênticas à dos verbos copulativos, exigindo apenas, diferentemente destes últimos, que o núcleo da oração pequena tenha um significado locativo".

Quanto à questão de se considerar que o PP que participa das construções com verbos do tipo ir e chegar é opcional na sintaxe, Xavier (1989) aponta que eles são saturados no léxico, a exemplo de verbos transitivos como os do tipo comer, e o PP nessas construções seria um caso de objeto opcional! Essa saída de Xavier (op. cit.) tem inclusive a ver com a necessidade de se preservar a estrutura binária dos nós ramificados, haja vista que, por serem esses verbos considerados inacusativos, selecionariam, a princípio, apenas um argumento, e este gerado numa posição de objeto direto com função- $\theta$ Tema. 
Apesar de essas proposições estarem coerentes com os fins a que elas predizem, a minha resposta, ao analisar os dados construídos com as preposições $a$, para e em com verbos do tipo ir e chegar no português, é negativa às três asserções apresentadas acima, o que implica assumir que considero o PP dessas construções como um argumento legítimo de V, c-selecionado e s-selecionado por ele. Que o PP não é opcional na sintaxe, ele pode vir não realizado foneticamente por questões de ordem discursiva. E que não deve ser tratado como núcleo de uma small clause por não apresentar acordo com um expletivo do tipo there do inglês e por apresentar restrições selecionais quanto a seus argumentos quando da variação entre as preposições.

\section{Evidências para a caracterização do status do PP em frases com verbos do tipo ir chegar: complemento ou adjunto?}

\subsection{O PP é complemento de V'}

Concernente à questão de o PP ser complemento legítimo de V em sentenças construídas com verbos do tipo ir e chegar, é possível pontuar que essa predição é captada pela seguinte evidência:

a) O teste da Clivagem ${ }^{6}$ : o PP complemento vem logo adjacente ao verbo (cf. em (8) e (9)), contrariamente ao que ocorre quando a preposição encabeça adjuntos (cf. em (10)):

(8) a. O João foi ao/para /no cinema. (*PE com em)

a'. Foi ir ao/para/no cinema o que o João fez.

a". *Foi ir o que o João fez ao/para/no cinema.

a",. *Foi ao/para/no cinema o que o João fez ir.

(9) a. O João chegou a/em casa. (*PE com $\mathrm{em}$ )

a'. Foi chegar a/em casa o que o João fez.

a".*Foi chegar o que o João fez a/em casa.

a" ".Foi a/em casa o que o João fez chegar.

(10) a. O João trabalha em Maceió.

a'. Foi trabalhar em Maceió o que o João fez.

a". Foi trabalhar o que o João fez em Maceió.

6 O teste da Clivagem aqui apresentado segue o padrão adotado em Farias (2003) a partir de Costa \& Costa (2001). 
Os dados acima parecem apresentar um aparente problema, que parece ainda não estar resolvido por aqueles que tratam o PP dessas construções como um adjunto: ao adotar os princípios das Teorias do Caso e Temática, compreendem-se as diferentes realizações da função gramatical das preposições $a$, para e em nos contextos estruturais dados. Isso implica então considerar que, ao assumir que o PP é complemento de $\mathrm{V}$, e que $\mathrm{P}$ atribui Caso inerente ao seu complemento, a função temática vai se dar composicionalmente a partir do complexo $\mathrm{V}+\mathrm{P}$, o que reforça ainda mais, segundo proposto em Farias (2004, 2005), o traço "half-way" dessas preposições. Bom, mas então, o problema em potencial que poderia surgir seria o fato de que, se eu considero a preposição, nesses contextos, um núcleo temático auxiliar, não seria a preposição barreira ao núcleo temático $\mathrm{V}$ na atribuição da função temática ao DP complemento de $\mathrm{P}$ ? O que me aparece como possível solução é considerar a noção auxiliar de LMarcação, o que compete verificar a relação existente entre uma categoria lexical e os complementos aos quais atribui uma função temática, conforme mostram os princípios de L- Marcação (cf. em (11)) associado à noção de Barreira (cf. em (12)) e à Condição de Minimalidade (cf. em (13)) abaixo:

\section{(11) L-Marcação}

A L-marca B sse A é uma categoria lexical que atribui uma função- $\theta$ a B.

\section{(12) Barreira}

Uma categoria $t$ é uma barreira sse $t$ é uma projeção máxima não L-marcada.

\section{(13) Condição de Minimalidade}

Entre $\mathrm{A}$ e $\mathrm{B}$ não intervém nenhum núcleo $\mathrm{X}^{0}$ tal que $\mathrm{X}^{0} \mathrm{c}$-comanda $\mathrm{B}$ e $\mathrm{X}^{0}$ não c-comanda $\mathrm{A}$.

Depreendo, então, que, por ser o PP subcategorizado por V, e como a noção de subcategorização está intrinsecamente relacionada à noção de s-seleção, é legitimo assumir que o PP não necessita de receber Caso de $\mathrm{V}$, mas sim o DP complemento de $\mathrm{P}$, o qual recebe do núcleo regente mais próximo: $\mathrm{P}$. Nesse sentido, $\mathrm{V}$ L-marca o PP já que participa da atribuição- $\theta$ do complemento de P. Como consequência, $\mathrm{P}$ não é barreira à regência de $\mathrm{V}$, pois é uma projeção 
funcional fraca, ao contrário do que acontece com as projeções fortes $\mathrm{C}$ e I. E para reforçar ainda mais essa assunção, dada a Condição de Minimalidade acima, verifica-se, ao traduzir A por V e B por $\mathrm{P}$, que não pode haver um elemento $\mathrm{X}^{0}$ interveniente a $\mathrm{V}$ e $\mathrm{P}$ c-comandando $\mathrm{PP}$, como podem ser evidenciados nos dados abaixo:

(14) a. *O João chegou [advp bem [pP a/em casa]].

b. *O João foi [advP sempre $[\mathrm{pp} \text { a/para/na cidade] }]^{78}$.

O resultado dessa interação de princípios me permite argumentar que: ao considerar a categoria lexical $\mathrm{V}^{0}$, em que rege e mcomanda o PP complemento, rege icualmente $\mathrm{P}$ e Spec de $\mathrm{P}$ (se houver), haja vista que, embora o PP seja uma projeção máxima excluindo $\mathrm{V}^{0}$ e dominando $\mathrm{P}$ e Spec de $\mathrm{P}$, é $\mathrm{L}$-marcado por $\mathrm{V}^{0} . \mathrm{V}^{0}$, no entanto, não rege o DP complemento de $\mathrm{P}$, porque o $\mathrm{P}$ é o regente mais próximo do DP do que $\mathrm{V}^{0}$, e, logo, exclui a regência de $\mathrm{V}^{0}$ an DP

7 É importante esclarecer que essas frases são estruturalmente bem formadas à medida que se considera que o advP está adjungido ao VP mais alto e não c-comanda o PP.

8 É relevante pontuar que há casos em que o advérbio pode ser interveniente a V e P, c-comandando o PP, ocupando, segundo as orientações de Duarte (2003) a posição Spec, PP, como pode ser evidenciado nos dados abaixo:

(i) O João chegou exatamente de Paris.

(ii) O João foi mesmo a/para/ em Maceió.

Como evidência para checar a assunção de que esses advérbios estão em Spec, PP, logo c-comandam o PP, Duarte (2003, p. 394) propõe o teste da deslocação e extração, em que, se há deslocamento do $\mathrm{PP}$, este tem de vir junto com o advérbio (cf. (iii)), ao passo que se há extração apenas de uma parte do PP, a sentença é agramatical, como mostram os dados em (iv):

(iii) a. [exatamente de Paris $]_{\mathrm{i}}$ o João chegou $[\mathrm{V}]_{\mathrm{i}}$

b [mesmo a/para/em Maceió $]_{i}$ o João foi $[\mathrm{V}]_{\mathrm{i}}$

(iv) a. *[ de Paris $]_{\mathrm{i}}$ o João chegou exatamente $[\mathrm{V}]_{\mathrm{i}}$

b. *[a/para/em Maceió] o João foi mesmo [V] $]_{i}$

Esses exemplos não me soam como contra-exemplos, já que não representam nenhuma implicação quanto à categorização do $\mathrm{PP}$ como complemento dos verbos do tipo ir e chegar nos contextos estruturais dados. 
complemento de $\mathrm{P}$ (cf. em (15)), o que não implica dizer que a função- $\theta$ não seja atribuída composicionalmente por $\mathrm{V}+\mathrm{P}$.

(15)

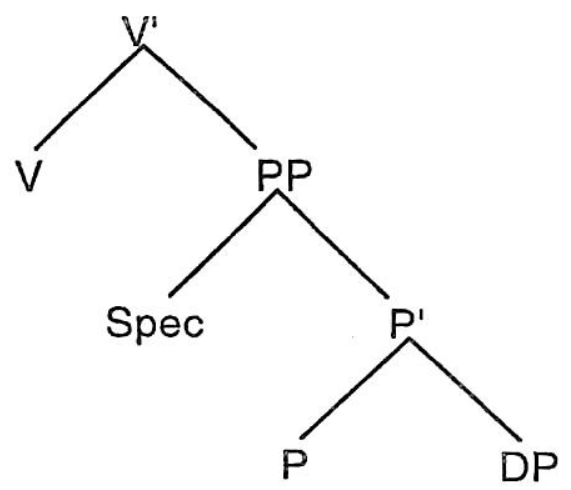

\subsection{O PP não é núcleo de uma small clause}

No tocante ao fato de o PP dessas construções ser tratado como núcleo de uma small clause, verifico que isso só faz sentido se se adotar o fato de que as construções inacusativas com PPs são derivadas de uma base como [e] is [SC[a man] [in the garden]], em que pode gerar dois tipos de frases: uma por aplicação de mover- $\alpha$, em que o SN a man é movido para receber Caso por acordo Spec-head: [A man i] is [sc[ $\mathrm{t}_{\mathrm{i}}$ ] [in the garden]], e outra em que se insere o there para satisfazer o princípio EPP, possibilitando a atribuição de Caso por transmissão dentro da CADEIA formada entre o expletivo e o NP sujeito da small clause: [There $\mathrm{i}$ ] is [sc[a man $\mathrm{i}$ ] [in the garden]] (Cf. CHOMSKY, 1981). A partir dessa observação e assumindo que as sentenças construídas com verbos do tipo ir e chegar + PP não devem ser tratadas como as frases copulativas, apresento as seguintes evidências:

(i) as frases construídas com verbos do tipo ir e chegar $+\mathrm{PP}$ não admitem acordo com um expletivo, como as construções com o there-insertion no inglês, derivadas de uma base como acima apresentada:

(16) a. *Expl. Foi o João ao/para/no cinema.

b. *Expl. Chegou o João a/em Lisboa. 
Fato curioso é que, mesmo no inglês, quando da presença do PP em construções "inacusativas" com verbos do tipo ir e chegar, a inserção do there é bloqueada, o que me leva a assumir, seguindo as pegadas de Xavier (1989), o fato de que esse DP argumento interno não deve ser tratado como tema, já que não é possível a coindexação com o par pro/expletivo:

(17) a. *There went a man at school.

b. *There arrived a man at/in the faculty.

Bem, mas voltando aos dados do português, a outra evidência para que o PP não seja tratado como núcleo de uma small clause é apontada a seguir:

(ii) Assumindo com Farias $(2004,2005)$ a predição de que as preposições $a$, para e $\mathrm{em}$ são preposições half-way e que juntas com o V formam um complexo, que é responsável pela atribuição da função- $\theta$ ao DP subcategorizado por P, é então plausível assumir que o PP dessas construções não pode ser tratado como núcleo de uma small clause, porque o complexo $\mathrm{V}+\mathrm{P}$ apresenta restrições selecionais em relação a seus argumentos, diferentemente do que é dado numa sentença copulativa:

(18) a O João foi ao/para/no cinema.

b *A carta foi ao/no cinema.

c O João foi embora para Portugal.

$d *$ J João foi embora a/em Portugal.

e O João chegou a/em casa.

$\mathrm{b} * \mathrm{O}$ João chegou para casa

\subsection{O PP não é opcional na sintaxe}

Já no que diz respeito à questão de esse argumento ser opcional na sintaxe, argumento que não, porque ele não exibe o mesmo comportamento de um objeto opcional de um verbo transitivo do tipo comer. A diferença se dá no sentido de que o PP das sentenças com verbos do tipo ir e chegar pode ser saturado na sintaxe em função de um contexto linguiístico mais amplo ou uma anáfora pragmática, como, por exemplo, no caso das respostas verbais em que o PP já é informação dada no contexto de pergunta (cf. (19)), ao passo que, quando se aplica mais uma vez o teste da clivagem, os contextos 
estruturais construídos com verbos do tipo ir e chegar não exibem um comportamento similar àqueles de objetos opcionais acusativos, que podem ser saturados no léxico (cf. (20)):

(19) a. O João foi ao/para o/no cinema?

a'. Foi.

a"'. O João foi.

(20) a. O João comeu (o bolo) bem?

a'. Foi comer bem o que o João fez.

a"'. Foi comer o que o João fez bem.

b. O João chegou a/em casa. (*PE com em )

b'. *Foi chegar o que o João fez.

c. O João foi ao/para o/ no cinema.

c'. *Foi ir o que o João fez.

\section{Considerações Finais}

Neste artigo, tive como objetivo precípuo trazer à tona a discussão sobre a distinção complemento $v s$. adjunto de verbos do tipo ir e chegar na gramática do português. Para isso tracei o seguinte percurso: contextualizei a situação e o problema relacionados à caracterização do status do PP como complemento ou adjunto desse tipo de verbo e apresentei evidências empíricas de que se trata de que o PP nos contextos estruturais dados trata-se de um complemento legítimo de V; não é opcional na sintaxe; não pode ser tratado como núcleo de uma small clause. Interessante perceber que essas evidências são motivadas não só por motivações sintáticas, mas sim pelas propriedades lexicais dos núcleos predicadores $\mathrm{V}+\mathrm{P}$, o que implica dedicar um tratamento diferençado quanto à caracterização e classificação desses PPs como adjuntos ou complementos do núcleo predicador verbal.

9 É pertinente esclarecer que ainda há muito a se dizer sobre os "objetos opcionais", já que, como pontuou Pustejovsky (1998), verbos com um comportamento semântico idêntico ao verbo comer, por exemplo, não licenciam "complement-drop": O cachorro devorou o bolo./*O cachorro devorou. 


\section{Referências}

BRITO, A. M.; DUARTE, I.; MATOS, G. Estrutura da frase simples e tipos de frases. In: MATEUS, M.H.M. et al. Gramática da língua portuguesa. Lisboa: Caminho, 2003. p. 433-507.

CHOMSKY, N. Lectures on government and binding. Dordrecht: Foris, 1981.

CHOMSKY, N. O conhecimento da língua, sua natureza, origem $e$ uso. Tradução Anabela Gonçalves e Ana Teresa Alves. Lisboa: Caminho, 1994.

CHOMSKY, N. \& LASNIK, H. A teoria de princípios e parâmetros. In: JACOBS et al. (eds). Syntax. Berlin-New York: Walter de Gruyter, 1993.

COSTA, A. \& COSTA, J. O que é um advérbio? Lisboa: Edições Colibri, 2001.

DUARTE, I. Prefácio à edição portuguesa. In: CHOMSKY, N. $O$ conhecimento da língua: sua natueza, origem e uso. Tradução Anabela Gonçalves e Ana Teresa Alves. Lisboa: Caminho, 1994.

DUARTE, I. A família das construções inacusativas. In: MATEUS, M.H.M. et al. Gramática da língua portuguesa. Lisboa: Caminho, 2003. p.507-548.

FARIAS, J. G. O estatuto sintático de preposições no português brasileiro. Dissertação de Mestrado. Universidade Federal de Alagoas, 2003.

FARIAS, J. G. Variação entre $a$, para e em no português brasileiro (PB) e no português europeu (PE): locus de microvariação sintática. In: Fórum Lingüístico da Nova, 2004. handout..., Lisboa, 2004. p.114.

FARIAS, J. G. Aspectos da sintaxe de preposições do português. 2005. Tese (Doutorado em Lingüística) - Maceió, Universidade Federal de Alagoas.

HOEKSTRA, T. \& MULDER, R. Unergatives as copular verbs: locational and existencial predication. The Linguistic Review, v. 7, n. 1, 1990. p. 1-79. 
KURY, A. G. Novas lições de análise sintática. São Paulo: Ática, 1997.

LEVIN, B. \& RAPPAPORT-HOVAV, M. Unaccusativity. at the syntax-lexical semantics interface. Cambridge, Mass.: MIT Press, 1995.

MATEUS, M.H.M. et al. Gramática da língua portuguesa. Lisboa: Caminho, 2003.

OLIVEIRA, M. Adjuntos e complementos verbais introduzidos pela preposição "a”. Ms. 2003.

PUSTEJOVSKY, J. The generative lexicon. London: Cambridge, MIT Press, 1998.

VIOTTI, E. C. A Sintaxe das sentenças existenciais do português do Brasil. Tese de Doutoramento. Universidade de São Paulo, 1999.

WILLIAMS, E. Predication. Linguistic Inquiry, v. 11, n. 1, 1980. p. 203-238.

XAVIER, M. F. Argumentos preposicionados em construções verbais: um estudo contrastivo das preposições $a$, de e to, from. Tese de Doutoramento. Universidade Nova de Lisboa, 1989. 